\title{
Comparison of $4 \%$ Topical Hydroquinone versus Combination of Oral Tranexamic Acid and 4\% Topical Hydroquinone in the Treatment of Epidermal Melasma
}

\author{
SARAH RIAZ ${ }^{1}$, NAJIA AHMED ${ }^{2}$, AYESHA ANWAR ${ }^{1}$, MOIZZA TAHIR $^{3}$, FARRAH YOUSAF ${ }^{1}$, SAMEENA KAUSAR $^{1}$ \\ ${ }_{1}^{1}$ Department of Dermatology, Pak Emirates Military Hospital, Rawalpindi, Pakistan \\ ${ }^{2}$ Department of Dermatology, Pak Emirates Military Hospital / National University of Medical Sciences, Rawalpindi, Pakistan \\ ${ }^{3}$ Department of Dermatology, Combined Military Hospital / National University of Medical Sciences, Rawalpindi, Pakistan. \\ Corresponding author: Najia Ahmed, Email: najiaomer@yahoo.com, Cell: 03325066303
}

\begin{abstract}
Objective: comparison of efficacy of topical $4 \%$ hydroquinone monotherapy with combination of oral tranexamic acid and topical $4 \%$ hydroquinone in the treatment of epidermal melasma

Study design: Quasi experimental study

Study period and place: Dermatology OPD, Pak Emirates Military Hospital Rawalpindi from July 2018 to January 2019.

Methodology: Total 80 patients presenting with epidermal melasma were selected from outdoor patient department after applying the inclusion criteria and consent was taken from selected patients. Study was started after getting permission from hospital ethical review board. Two treatment groups were made after dividing patients by using alternate method. Treatment with topical $4 \%$ hydroquinone alone was started for group A patients and combination of capsule tranexamic acid (250 mg two times a day) along with topical $4 \%$ hydroquinone were started for group B patients for the next 6 months. Evaluation of patients through detailed history, clinical and wood's light examination before starting therapy and after of 24 weeks of treatment was done for both groups. Efficacy of treatment was assessed via Modified MASI score.

Results: Hydroquinone monotherapy was effective in $21(52.5 \%)$ patients among group A while in group B patients, combination treatment i.e. oral tranexamic acid and topical hydroquinone, was effective in $31(77.5 \%)$ patients $(p$ value $=0.01)$. Conclusion: Effectiveness of Hydroquinone 4\% topical therapy combined with oral tranexamic acid for epidermal melasma is better than topical $4 \%$ hydroquinone alone.
\end{abstract}

Key words: Epidermal melasma, oral tranexamic acid, topical $4 \%$ hydroquinone.

\section{INTRODUCTION}

An acquired symmetrical hyper melanosis (increased pigmentation) of face is termed as melasma. It is a pigmentary skin disorder comprising of brown to greyish macules and patches with irregular border on sun exposed areas of skin ${ }^{1}$. It is a worldwide problem affecting thousands of people, especially seen in Fitzpatrick skin photo types III-V having female predisposition ${ }^{2}$. Depending upon the area of localization, there are three clinical patterns-Centro facial, malar, and mandibular. Histologically we can divide this condition into three types: epidermal, dermal, and mixed depending upon depth of involvement of epidermis and dermis. Wood's light examination demonstrates increased pigmentary intensity in melasma, with epidermal component but not seen with melasma having dermal component ${ }^{3}$.

Treatment of melasma is challenging because of its complex pathogenesis. Factors like genetic background along with female sex hormones and sun light exposure are basic culprits in its pathogenesis. Endocrine abnormalities involving ovaries along with their tumors and thyroid dysfunctions are also involved. External agents like cosmetic products, nutritional deficiencies, intake of photo allergic or phototoxic drugs and antiepileptic agents are some important factors associated with this pigmentary disorder ${ }^{4}$. During pregnancy certain hormone changes also contribute to development of melasma along with other normal physiological changes like darkening of the nipples and linea nigra. In patients who have acquired melasma during pregnancy or OCP use may show fading of pigmentation after pregnancy or stoppage of pills but it is often persistent ${ }^{5}$. Diagnosis of this skin condition is done clinically and confirmation of subtype is done via woods lamp examination and histopathology of lesion.

Melanin production and degradation cycle are the mains target points for all melasma therapies including topical agents and resurfacing procedures. Hydroquinone (HQ) remains a workhorse for treatment of melasma and is often considered as the "gold standard" 6 . HQ or dihydroxy benzene, is structurally similar to precursors of melanin. Melanin synthesis is inhibited via tyrosinase inhibition leading to decresed conversion of DOPA to melanin. At least 4-6 weeks are required for a visible response. However good to excellent results were obtained in $55 \%$ of patients after two months treatment with hydroquinone. ${ }^{7}$
Tranexamic Acid (TXA) is a relatively new and effective agent for the melasma management. TXA is a lysine analog. Its works by reducing photo-precipitated plasmin activity in keratinocytes. This results into decreased free arachidonic acid levels locally in skin resulting into decreased prostaglandins production. This decreased prostaglandins leads to diminished tyrosinase kinase enzyme activity within melanocytes. Combining oral TXA with $\mathrm{HQ}$ gave well to excellent response in $82.3 \%$ of patients after taking treatment for 3 months. ${ }^{8}$

The objective of our study was to compare the efficacy of topical 4\% HQ versus capsule (cap) TXA administered orally in addition to topical $4 \% \mathrm{HQ}$ for epidermal melasma treatment. We conducted this study because melasma is a very distressing condition and does not has a cure which is $100 \%$ effective or permanent.

Worldwide many clinical trials have been done for tranexamic acid effectiveness in melasma but data for our population is scarce. There was high variability in treatment response shown by these few conducted studies. Therefore, we carried out this study as TXA is safe and inexpensive. If found effective, it can be a very useful addition to the treatment of melasma.

\section{METHODOLOGY}

This quasi experimental study was carried out at the department of dermatology in Pak Emirates Military Hospital Rawalpindi for 6 months starting in July 2018 and finishing in January 2019. Approval from the hospital ethical review committee was taken (certificate no A/28/346/2021). WHO sample size calculator was used for sample size measurement.

Level of significance was $5 \%$, power $90 \%$, anticipated population proportion (P1) was $=82.3 \%^{8}$ and anticipated population ( $(P 2)$ was $=55 \%$. 40 patients were enrolled in each group after taking informed consent. Non probability consecutive sampling was used for selection of patients. Wood's light examination was used to diagnose epidermal melasma as it's light intensifies color of pigment in skin lesions.

Patients with the age groups not less than 15 years and not more than 60 years were enrolled in the study. Patients who received topical or oral treatment for melasma during the last one 
month were excluded from our study. Females who were pregnant or lactating were also not included. Other factors for exclusion were history of cardiac, renal disease, malignancy or undergoing any sort of chemotherapy or radiotherapy.

A detailed history was taken followed by clinical examination. Relevant clinical details were endorsed on a specially formulated proforma. Alternate method was used for dividing patients into two equal treatment groups. Only topical $4 \%$ hydroquinone was given to group A patients and a combination of oral TXA $(250 \mathrm{mg})$ twice daily and topical $4 \%$ hydroquinone was given to group $B$ patients for 6 months.

The assessment was done on the basis of modified MASI score at the start of the treatment and then after completing 6 months of the therapy.

Modified MASI score was calculated as $0.3 \mathrm{~A}(\mathrm{~F}) \mathrm{D}(\mathrm{F})+0.3 \mathrm{~A}(\mathrm{LM}) \mathrm{D}(\mathrm{LM})+0.3 \mathrm{~A}(\mathrm{RM}) \mathrm{D}(\mathrm{RM})+0.1 \mathrm{~A}(\mathrm{C}) \mathrm{D}(\mathrm{C})$

Where $D$ is for Darkness with grade $0=$ absent, $1=$ slight, $2=$ mild, $3=$ moderate and $4=$ severe $A$ is for Area having grade $0=$ no involvement, 1 is $<10,2=10-29 \%, 3=30-49,4=50-69,5=70-$ $89 \% 6=90-100 \%$. F is forehead, MR stands for right malar area which is equal to 0.3 of total face area and ML is left malar area while $C$ is chin. The values 0.3 and 0.1 are respective percentages of the total facial area. The minimum score for Modified MASI is 0 and maximum is 24 .

SPSS version 23 was used for assessment and analysis of data. Mean along with standard deviation were calculated for quantitative variables e.g. age and duration of disease while frequency and percentage were determined for qualitative variables like gender and efficacy. Chi-square test / Fisher's exact test were used to compare the efficacy of both the treatment groups. A P value of less than 0.05 was marked as significant.

\section{RESULTS}

In group $A$, total range of age of patients was $20-40$ years with a mean of $30.28+6.60$ years where as in group $B$, it was $18-39$ years with a mean of $29.13+6.63$ years.

Gender ratio among patients who received treatment for melasma is shown is in Figure 1.

Comparison of efficacy of topical hydroquinone alone with combination of oral TXA and $4 \%$ hydroquinone applied topically for treatment of epidermal melasma is shown in table 1.

Stratification of efficacy with regards to duration of illness was recorded and presented in Figure 2.

Table 1: Comparison Of Efficacy Of Topical 4\% Hydroquinone With Combination Of Oral Tranexamic Acid And Topical 4\% Hydroquinone In The Treatment Of Epidermal Melasma $(\mathrm{N}=80)$

\begin{tabular}{|l|l|l|l|l|}
\hline \multirow{2}{*}{ Efficacy } & \multicolumn{2}{|l|}{$\begin{array}{l}\text { Group-A } \\
(\mathrm{n}=40)\end{array}$} & $\begin{array}{l}\text { Group-B } \\
(\mathrm{n}=40)\end{array}$ \\
\cline { 2 - 5 } & No. of patients & $\%$ & No. of patients & $\%$ \\
\hline Yes & 21 & 52.5 & 31 & 77.5 \\
\hline No & 19 & 47.5 & 9 & 22.5 \\
\hline Total & 40 & 100 & 40 & 100 \\
\hline
\end{tabular}

$\mathrm{P}$ value $=0.01$

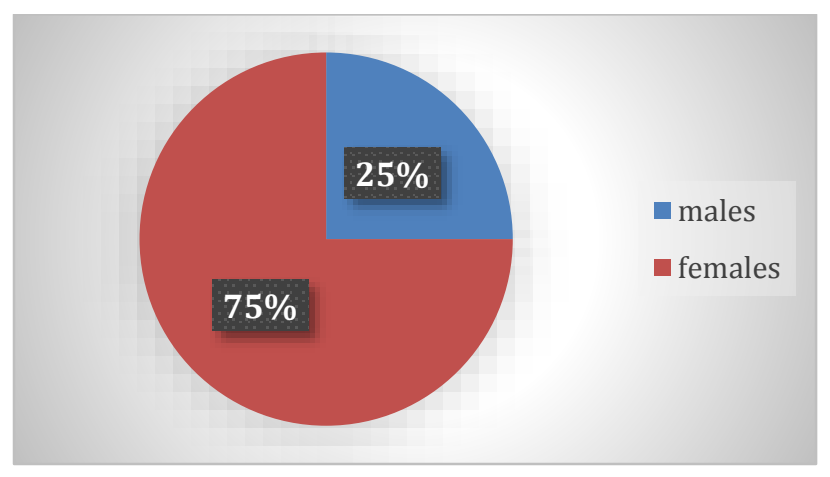

Figure1: GENDER DISTRIBUTION AMONG PATIENTS WITH MELASMA $(\mathrm{n}=80)$

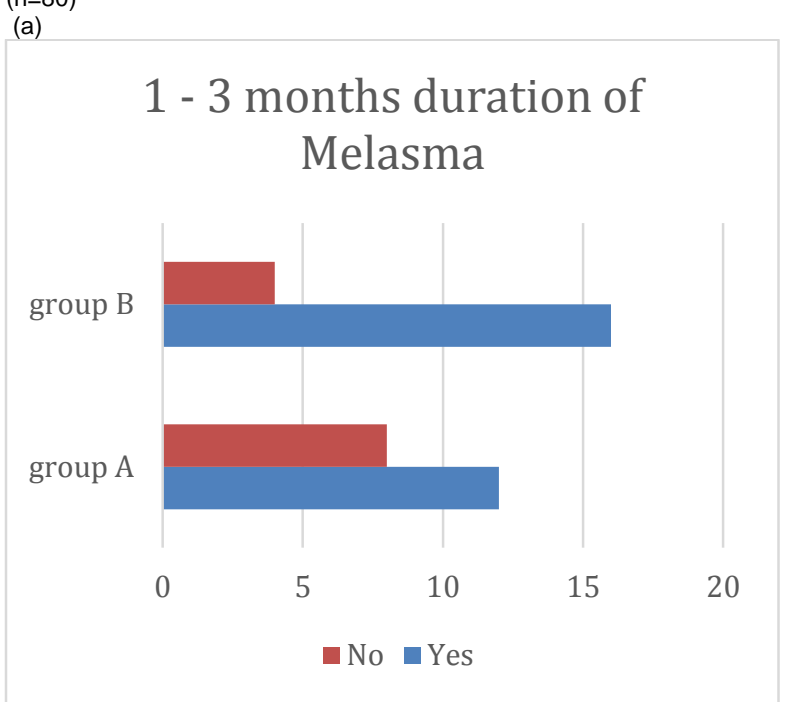

(b)

\section{$>3$ months duration of Melasma}

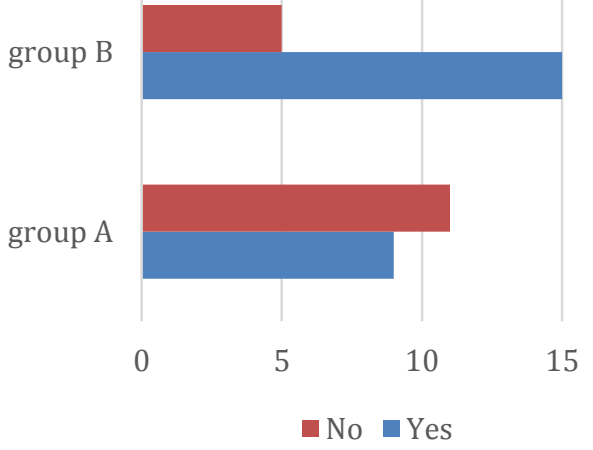

20

Figure 2 A \& B: Stratification For Efficacy With Regards To Duration Of Illness

\section{DISCUSSION}

Topical agents either used alone or in combination are most common treatment modality for melasma. ${ }^{9}$ Epidermal type of melasma is more responsive to topical therapies. The depigmentation becomes evident after 5-7 weeks of continuous daily application. Topical $\mathrm{HQ}$ treatment requires continuous application for at least three months, and can be used up to 6 months as shown in a study by Kumaran et $\mathrm{al}^{10}$ which is similar to response of $\mathrm{HQ}$ in our study.

Side effects of $\mathrm{HQ}$ depend on the duration of application, its concentration and amount of drug applied. Acute reactions like irritation and burning sensation are common. Long term adverse effects including exogenous ochronosis, pigmented colloid milia development, sclera and nail discoloration and reduction in skin elasticity ${ }^{11,12}$. None of these side effects occurred in our study except for local erythema and burning sensation.

A study conducted by Zhang- et al showed negative effect of TXA on the catalytic reaction of tyrosinase resulting into inhibition of melanin production ${ }^{13}$. In the management of melasma, TXA can be administered through three routes which are oral 
intake, topical application and intradermal microinjections. Its dose for hemostasis is $1000 \mathrm{mg} 3$ times a day ${ }^{14}$, while for melasma its only $250 \mathrm{mg}$ to $500 \mathrm{mg}$ twice a day ${ }^{15}$. We used the dose of $250 \mathrm{mg}$ twice daily as used in most other studies. ${ }^{7,13,15,16}$ The difference between results of two groups in our study was significant at the end of 24 weeks of treatment as depicted by high ratio of clinical improvement of melasma in group $B$ as compared to group $A$.

In 2013 a study was conducted by Cho et al. In this study they randomly divided fifty-one patients with melasma into 2 groups. Group A was started with oral tranexamic acid along with IPL and laser treatments (group A) and group B treated with only IPL and laser. Modified MASI score was more reduced in group A in which tranexamic acid was used $(p=0.005)$. No significant side effects were seen up to 8 months of oral TXA medication ${ }^{16}$. These results for oral TXA are similar to our study.

Wu et al conducted a study in which TXA 250mg twice daily was used to treat 74 Chinese patients with melasma. The response of treatment was measured by two physicians and by the patients based on the decrease in size of melasma and improvement of pigmentation. The results were excellent, fair and poor in $10.8 \%, 54 \%, 31.1 \%$ and $4.1 \%$ patients respectively. The common side effects of oral trexenemic acid were gastrointestinal discomfort and decreased menstruation. 9.5\% patients showed recurrence of lesions after treatment but these were patients using oral TXA as single agent ${ }^{17}$. The efficacy of TXA in this study is comparable to our study.

A retrospective study at a tertiary dermatological center in Singapore analyzed effect of oral TXA in dose of $250 \mathrm{mg}$ twice a day in patients with refractory melasma who have used different topical combination treatments. The mean MASI post treatment scores with oral TXA treatment $(2.7 \pm 1.6)$ were significantly less $(P<0.01)$ after a mean period of $3.7 \pm 0.33$ months treatment as compared to those before treatment $(8.8 \pm 4.2)$. There was $69 \%$ mean improvement in MASI score proving the effectiveness and safety of low dose TXA in management of refractory melasma ${ }^{18}$. The result for TXA was similar to that in our study.

Tranexamic acid has also been used topically in the form of injections and with micro needling.

A randomized study was done prospectively for 60 patients who were divided in 2 groups. One group received localized microinjections of TXA and second group was treated with TXA with micro-needling at an interval of 0,4 and 8 weeks. Microinjection group showed $35.72 \%$ improvement in the MASI score while microneedling group showed $44.41 \%$ improvement ${ }^{19}$. We did not consider this option in our study. Futher studies are to be commenced in this regard.

A study done in 2013 treated patients with two TXA tablets $250 \mathrm{mg}$ three times a day and topical TXA agent twice a day for 8 weeks. There was 49\% decrease in Modified Melasma Area and Severity Index (mMASI) score in the TXA group as compared to $18 \%$ in the control group ${ }^{20}$ showing efficacy of TXA in keeping with our study.

Del Rosario et al conducted a study showing combining of $4 \%$ topical hydroquinone cream with oral tranexamic acid resulted into more improvement of epidermal melasma as compared to $4 \%$ topical hydroquinone alone. Their results further support our study outcomes. ${ }^{21}$

Lajverdi et al conducted a study over 100 eligible patients having symmetric facial melasma. All patients were assigned to either $250 \mathrm{mg}$ thrice daily oral TXA plus $\mathrm{HQ} 4 \%$ cream nightly or $\mathrm{HQ} 4 \%$ cream only. Treatment was continued for 6-month and the overall mean of the MASI score in oral TXA and topical HQ group group was 1.8 points lower than in topical $H Q$ only group $(P$ $=0.015$ ). Treatment satisfaction rate was higher in oral TXA group than topical $\mathrm{HQ}$ alone group as $82.2 \%$ in first group vs. $34.95 \%$ in second group $(P<0.001)^{22}$.

Shihab et al conducted a study on melasma patients comparing $\mathrm{HQ} 4 \%$ cream, sunscreen and oral TXA in one group and $\mathrm{HQ} 4 \%$ cream, sunscreen and placebo capsules in other group for 3 months. There was a $42 \%$ reduction of mMASI as compared to baseline in Group A vs. $4.7 \%$ in Group B after 3 months of treatment. Results of this study was in favor of more effectiveness of combination of oral TXA with topical $\mathrm{HQ}$ as compared to topical $\mathrm{HQ}$ alone ${ }^{23}$ similar to our study.

A randomized, double-blind, comparative trial was carried out using kojic acid, emblica extract and glycolic acid on 80 patients of mixed ethnicities with facial dyschromia. ${ }^{24}$ This treatment formula was compared with $4 \%$ hydroquinone cream. No statistical difference was obtained between both sides $(\mathrm{P}$ value $<$ 0.05). Our combination compared with $\mathrm{HQ}$ alone had a significant difference with regards to its efficacy.

Our findings are in agreement with the findings of NavarreteSolis $\mathrm{J}$, who revealed that with 8 weeks treatment with hydroquinone demonstrating well to excellent results in $35 \%$ of patients ${ }^{7}$.

A study done in 2012 showed excellent results with oral tranexamic acid combined with hydroquinone in $82.3 \%$ of their patients with 3 months treatment ${ }^{8}$.

The limitation of our study is that we did not follow our patients beyond treatment period to see sustained response or otherwise. More studies should be conducted with larger sample size and longer duration.

\section{CONCLUSION}

Efficacy of $4 \%$ topical hydroquinone cream in combination with oral tranexamic acid is better than $4 \%$ topical hydroquinone for management of epidermal melasma. However further studies involving larger number of patients should be done to validate our results and to find out better treatment modality which will be further helpful for treatment and management protocol

Conflict of Interest: There is no conflict of interest.

\section{REFERENCES}

1. Ogbechie-Godec OA, Elbuluk N. Melasma: an up-to-date comprehensive review. Dermatol Ther. 2017; 7(3):305-18.

2. Satish D A, Aparna A D, Radhika V K. A clinico-epidemiological study of melasma in 402 patients in an office-based practice. Clin Dermatol Rev 2019;3:154-6.

3. Chuah SY, Thng TG. Diagnosis of melasma in brown skin: Wood's lamp, dermoscopy, and confocal microscopy. In Melasma and Vitiligo in Brown Skin Springer, New Delhi. 2017; 41-49.

4. Bhattarai S, Pradhan K, Sharma S, Rajouria EA. Clinical patterns and epidemiological characteristics of melasma in a tertiary care hospital of Nepal. Pigment Int. 2017; 4(1):35.

5. Maddaleno AS, Camargo J, Mitjans M, Vinardell MP. Melanogenesis and Melasma Treatment. Cosmetics. 2021; 8(3):82. https://doi.org/10.3390/cosmetics8030082

6. McKesey J, Tovar-Garza A, Pandya AG. Melasma treatment: an evidence-based review. Am J Clin Dermatol. 2020; 21(2):173-225.

7. EA, Timalsina M. Oral Tranexamic Acid for the Treatment of Melasma. Kathmandu Univ Med J. 2012;10:40-43

8. Navarrete-Solís J, Castanedo-Cázares JP, Torres-Álvarez B, OrosOvalle C, Fuentes-Ahumada C, González FJ, et al. A Double-Blind, Randomized Clinical Trial of Niacinamide $4 \%$ versus Hydroquinone 4\% in the Treatment of Melasma. Dermatol Res Pract.2011;2011:1-5

9. Komal S, Mashhood A, Farooq M, Qayyum N. A comparison of efficacy of intradermal tranexamic acid with topical $20 \%$ azelaic acid in the treatment of melasma. Pak Armed Forces Med J, 2021; 71(2), 494-97.

10. Kumaran MS, Narayan RV, Kaushik A, Bishnoi A, Vinay K, Parsad D. Clinico-epidemiological profile and long term follow up in melasma. Dermatologic Therapy. 2021; e15143. doi:10.1111/dth. 15143

11. Neagu N, Conforti C, Agozzino M, Marangi GF, Morariu SH, Pellacani G, Persichetti P, Piccolo D, Segreto F, Zalaudek I, Dianzani C. Melasma treatment: a systematic review. J Dermatologic Treatment. 2021; 14:1-39. DOI: 10.1080/09546634.2021.1914313

12. Sunkara HP, Kilaru KR, Kumar AP, Ramineni HB, Krishna PR. A case report on hydroquinone induced exogenous ochronosis. Int $\mathrm{J}$ Adv Med. 2020;7(2):337.

13. Zhang $X$, Yang $X$, Yang $H$, Yang $Y$. Study of inhibitory effect of acidum tranexamicum on melanin synthesis. Chin J Dermatovenerol Integr Tradit West Med. 2003;2:227-9. 
14. Qayum M, Ali W, Waheed N. Post partum hemorrhage prevention with tranexamic acid is effective and safe in comparison to placebo. Pak Armed Forces Med J, 2020; 68(4), 908-913.

15. Bala HR, Lee S, Wong C, Pandya AG, Rodrigues M. Oral tranexamic acid for the treatment of melasma: a review. Dermatol Surg. 2018;44(6):814-25

16. Cho $\mathrm{HH}$, Choi $\mathrm{M}$, Cho $\mathrm{S}$, Lee $\mathrm{JH}$. Role of oral tranexamic acid in melasma patients treated with IPL and low fluence QS Nd: YAG laser. J Dermatol Treat. 2013;24(4):292-6.

17. Wu S, Shi H, Wu H, Yan S, Guo J, Sun Y, Pan L. Treatment of melasma with oral administration of tranexamic acid. Aesthetic Plast Surg. 2012;36(4):964-70.

18. Tan AWM, Sen P, Chua SH, Goh BK. Oral tranexamic acid lightens refractory melasma. Australas J Dermatol. 2017;58(3):e105-e108.

19. Budamakuntla L, Loganathan E, Suresh DH, Shanmugam S Suryanarayan $S$ et al. A randomised, open-label, comparative study of tranexamic acid microinjections and tranexamic acid with microneedling in patients with melasma. J Cutan Aesthet Surg. 2013;6(3):139.

20. Na Jl, Choi SY, Yang SH, Choi HR, Kang HY, Park KC. Effect of tranexamic acid on melasma: a clinical trial with histological evaluation. J Eur Acad Dermatol Venereol. 2013;27(8):1035-9.
21. Del Rosario E, Florez-Pollack S, Zapata Jr L, Hernandez K, TovarGarza A, Rodrigues M, Hynan LS, Pandya AG. Randomized, placebo-controlled, double-blind study of oral tranexamic acid in the treatment of moderate-to-severe melasma. J Am Acad Dermatol. 2018;78(2):363-9.

22. Lajevardi V, Ghayoumi A, Abedini R, Hosseini H, Goodarzi A, Akbari $Z$, Hedayat K. Comparison of the therapeutic efficacy and safety of combined oral tranexamic acid and topical hydroquinone $4 \%$ treatment vs. topical hydroquinone $4 \%$ alone in melasma: a parallelgroup, assessor-and analyst-blinded, randomized controlled trial with a short-term follow-up. J Cosmet Dermatol. 2017;16(2):235-42.

23. Shihab N, Prihartono J, Tovar-Garza A, Agustin T, Legiawati L, Pandya AG. Randomised, controlled, double-blind study of combination therapy of oral tranexamic acid and topical hydroquinone in the treatment of melasma. Australas J Dermatol. 2020;61(3):23742.

24. Babbush KM, Babbush RA, Khachemoune A. Treatment of melasma: a review of less commonly used antioxidants. International Journal of Dermatology. 2021;60(2):166-73. https://doi.org/10.1111/ijd.15133 